\title{
The Level of Representation of Arabic Language Books for the Basic Stage in Jordan for the Psychological Foundations of the Curriculum from the Point of View of teachers in Ma'an Governorate
}

\author{
Jazzah M. Alrfou \\ Instructor at the Ministry of Education,Email: jazza75rfu@gmail.com
}

\begin{abstract}
The aim of this study was to find out the level of representation of Arabic language books for the basic stage in Jordan for the psychological foundations of the curriculum from the point of view of its teachers in the schools of Ma'an Governorate. The study sample consisted of (110) teachers who teach the lower basic stage: $\left(1^{\text {st }}, 2^{\text {nd }}, 3^{\text {rd }}\right.$, $4^{\text {th }}$ ) in the first semester of the academic year 2018/2019, the researcher used the descriptive approach.In order to achieve the objective of the study; the researcher developed a classification of psychological foundations, after verifying its validity and reliability. The researcher used statistical treatments, T-Test, One Way ANOVA, Tukey HSD for post comparisons, using the SPSS program,the study concluded that the Arabic language books for the lower basic stage in Jordan represent the psychological foundations to a medium degree and with an average of (3.53) in general, where the field of linguistics reached the highest of the mean of (3.86), with a high level, The lowest was the physical domain, with an average of (3.44), and a medium degree, as the study showed: the absence of statistical significance differences, attributed to the variables: (gender and experience). The results also suggest that there are statistically significant differences due to the variable of scientific qualification for the benefit of the postgraduate studies. The study recommends that the development of the Arabic language books for the lower basic stage be reconsidered by the management of books and school curricula in the Ministry of Education, to a high degree. The study also recommends further evaluation studies of the Arabic language textbooks for the lower basic stage.
\end{abstract}

Keywords: Arabic Language Books, Psychological foundations, Lower basic stage, Level of Representation DOI: $10.7176 / \mathrm{JEP} / 10-4-12$

\section{Introduction}

Curriculum development should be of great importance in order to keep abreast of developments and focus on thinking skills, societal and national values, and the Arabic language curriculum, like other curricula, need to be followed up and continued in the development and implementation of programs to promote the Arabic language and provide a learning environment that stimulates education and responds to different needs (Ministry of Education, 2007), and the psychological needs of students must be met, among these needs:

1. The need to recognize students' abilities and talents.

2. The need for self-insight into their readiness and awareness.

3. The need for independence and freedom of expression.

4. Sense of security and non-threat.

5. The need for more Care (Mekhemer, 2013).

The curriculum of the Arabic language needs to be pursued and continued in the development and implementation of programs; to promote the Arabic language and to provide a learning environment that stimulates education and responds to different needs (Ministry of Education, 2005).

Ashour (2004) asserts that he relies entirely on Arabic language in the formulation of student thought, because it contains knowledge and texts of reading, affect the students' thinking and knowledge, and depend on them in determining the quality of learning for students. 
It has called for several conferences and focused on the need to update curricula and follow a new mechanism in the preparation, including the Amman Conference 1987: the first Jordanian conference for educational development, where many of the educational issues were discussed, the fifth recommendation at the Conference focused on the need for a new mechanism for curriculum development, taking into account the active participation of different sectors of society and the need to ensure that the activities included in textbooks are functional and linked to society and the environment (Ministry of Education, 1988).

The recommendations of the Educational Development Conference held in Amman in 2015, the need to continue to develop curricula in specialized educational studies, the need to keep abreast of developments and focus on thinking skills and community and national values (Ministry of Education, 2015).

The process of developing and building the curriculum must be based on a set of cognitive, social, philosophical and psychological bases that take into account the needs, motivations and interests of students in all aspects: mental, emotional, social, psychological, linguistic and religious (Al-Sameer 1994).

\section{The foundations of the school curriculum}

The curriculum is based on a set of foundations set by the psychologists namely:

1. The philosophical foundations: We mean the intellectual frameworks on which the curriculum is based, the definition of its inputs, and the formulation of its content, in line with the specificity of the community, represented by its faith, its heritage, the duties of its members and the rights owed to them.

2. Psychological foundations: We mean the set of characteristics and procedures that relate to the nature of students, their psychological characteristics, and the factors affecting their different developmental stages, and the founders of the curriculum must highlight the capabilities of students, and their needs and problems, and linking them to the curriculum, in line with the theory of learning.

3. Knowledge bases, namely: The foundations of knowledge, its conceptual structure, the nature of thinking and it is necessary to emphasize the relationship between knowledge, attitudes, and different skills.

4. Social foundations: It is the cornerstone, which has the greatest impact on the construction and implementation of the curriculum, which are the principles, values and cultural heritage prevailing in society, and its philosophical and social characteristics and social system (Abu Saalik 1999, Bataina 2004).

The psychological foundations are defined as: the set of psychological principles, which the studies of psychology, and its research, have reached on the nature of the learner, the characteristics of his growth, his needs, his tendencies, his abilities, and his preparations (Altalafah 2013).

And some of them went to: a set of factors that relate to the nature of the learner, the characteristics of his growth, his needs, his tendencies, his abilities, his preparations, and the nature of learning, which must be taken into consideration when developing the curriculum (Al Saudi and Al-Hawamdah, 2016).

It can be divided as follows:

First: psychological foundations related to the developmental characteristics of students, and can be divided into six areas: mental, linguistic, physical, social, emotional, and religious.

Second: psychological foundations related to the needs of students.

Third: psychological foundations related to students' attitudes.

We will talk about each of these three axes:

First: psychological foundations related to the developmental characteristics of the learner

Growth refers to behavioral changes resulting from maturation and learning interaction, it can be studied by crosscutting or longitudinal methods, and cognitive development studies are concerned with the development of thinking and methods of learning the world.

Piaget believes that cognitive development is the outcome of the interaction between the individual and the environment, and that the child, through this interaction, not only gains direct experience but also learns how to deal with the surrounding environment (Dahiri, 2011).

The growth aspects of students can be summarized as follows: physical, mental, social, emotional, psychological, linguistic, religious and moral growth. 
Second: psychological foundations related to the needs of learners

The educators differed in interpreting the meaning of need, some of them go to the need: they are a set of behaviors that the young do not have, and the adults want to give them, and others see the need: a goal the individual seeks to achieve; because it achieves self-satisfaction and get rid of internal tensions felt (Alsayed1998).

(Mukhemer 2013) defines them as the basic demands of the individual's psychological growth, which he must learn to become happy in his life.

Amal (2015) noted that psychologists recognized the need: as a physiological state within the individual, which made him tend to do different kinds of behavior towards certain goals, and that his tendency towards behavior reduced his tension and made him get rid of the state of imbalance.

Third: The psychological foundations related to the trends of learners

Habadasah (2014) defines trends: as an individual's thoughts, feelings, and attitudes towards a particular subject. Al-Jadua (2015) defines it as the tendency of an individual to behave in a way, positive or negative, towards something, and may be a person, group or idea.

Everyone agrees, as jadoe pointed out in 2015 , on the importance of trends in the life of the individual, the study of the trend in the psychological and educational fields plays a large role in view of the relationship between the behavior and the impact of the trend.

\section{Study problem and its questions}

Arabic language books are of great importance. They are the first pillar of the thinking process and it is the first means of communication and understanding and communication and broadcast feelings, which is the official language in the educational process of learning, in the stages of the education process (Ministry of Education 2015). And therefore must take into account the psychological needs of pupils and their developmental characteristics, as the learner is the focus of the educational process, this must be reflected in the textbook, to focus on the attention to the psychological aspects of students in terms of meeting their needs and desires and achieve comprehensive growth, and because the teacher is based on achieving the goals and the translation of the curriculum, and in response to the Amman conference in 2015, and the importance of psychological foundations, this study was conducted in order to determine the level of representation of Arabic language books for the basic stage of the psychological foundations of the curriculum, from the point of view of teachers in Ma'an Governorate. This study was an attempt to answer the following questions:

1. "What is the level of representation of Arabic language books for the lower basic stage in Jordan for the psychological foundations of the curriculum from the point of view of teachers in the governorate of Ma'an?"

2. Are there statistically significant differences at the level of significance $(\alpha \leq 0.05)$, in the views of Arabic language teachers for the lower basic stage in their estimate of the level of representation of Arabic language books for the basic stage of the psychological foundations of the curriculum according to the gender variable?"

3. Are there statistically significant differences at the level of significance $(\alpha \leq 0.05)$, in the views of Arabic language teachers for the lower basic stage in their estimate of the level of representation of Arabic language books for the basic stage of the psychological foundations of the curriculum according to the scientific qualification variable?"

4. Are there statistically significant differences at the level of significance $(\alpha \leq 0.05)$, in the views of Arabic language teachers for the lower basic stage in their estimate of the level of representation of Arabic language books for the basic stage of the psychological foundations of the curriculum according to the experience variable?"

\section{Objectives of the Study}

This study aimed at the following:

1. Investigating the level of representation of Arabic language books for the lower basic stage in Jordan for the psychological foundations of the curriculum from the point of view of teachers in Ma'an Governorate. 
2. Identifying the difference of opinion of teachers of the Arabic language for the lower basic stage, in their estimation of the level of representation of the books of the psychological foundations of the curriculum according to the variables (scientific qualification, gender, experience).

\section{Significance of the Study}

1. This study may reveal the level of representation of Arabic language books for the basic stage in Jordan, the psychological foundations of the curriculum, which stem from the growth characteristics of students, from different aspects and their needs and trends.

2. Helps the teacher to know the psychological aspects, which must be observed by students; to improve their performance and stimulate their motivation and the formation of their desire towards the process of learning.

\section{Study limits and limitations}

- Human and spatial boundaries: This study was limited to a sample of male and female teachers of the Arabic language for the basic stage in the schools of the directorates of education for Ma'an governorate (Southern Badia, Ma'an region, Petra Brigade, Shuibik Brigade).

- Time Limits: This study was conducted in the first semester of the academic year (2018/2019).

- The results of this study are determined by the degree of reliability and stability of the tool developed, and the objectivity of the response presented by the study sample.

\section{Procedural definitions}

Level of representation: The level that the male and female teachers of the Arabic language in the representation of the Arabic language books for the basic stage of the basic psychological foundations and reflect the level obtained, the current tool used in the study.

Psychological foundations: The psychological foundations can be defined as a set of determinants and principles that scientists have reached in the field of psychology, about the nature of the learner and its developmental characteristics in all aspects, his needs, his preparations, his wishes, his tendencies, and his trends.

The basic minimum stage: are the ranks of the minimum basic education level in Jordan, students are between 911 years old, include (fourth, fifth, sixth) grades.

\section{Arabic language books}

It is the Arabic language school taught in the Hashemite Kingdom of Jordan for 2018/2019 issued by the Ministry of Education and includes:

- The Arabic language book, the texts of the listening texts and the calligraphy book, for the fourth grade, the Arabic Language Book and the Texts of Listening Book The Arabic calligraphy book for the fifth grade, the Arabic Language Book and the Texts of the Hearing Book The Arabic calligraphy book for the sixth grade, all issued by the Ministry of Education Decree No. (36/2017), dated 17/1/2017, starting from the academic year 2017/2018, based on the decision of the Higher Education Council No. 89/2016.

Arabic language teachers for the basic minimum phase

They are the male and female teachers who teach the Arabic language for the basic stage, which includes fourth, fifth and six grades in the schools of Ma'an governorate in the first semester of the academic year 2018/2019.

\section{Previous studies}

The study of Al-Rifa'i (2018) came to know the degree to which the Arabic language books take into consideration the basic stage of the psychological foundations from the point of view of its teachers in Tafila governorate, where the study sample consisted of (83) male and female teachers who teach the basic stage. The researcher used the descriptive method. The study concluded that the Arabic language books for the upper elementary stage take into account the psychological bases in a medium degree. With an average of (3.55), in general, where the field of 
language get the higher Average arithmetic reaching (3.88) at a high level, the lowest of which was the physical area, with an average of (3.51) with a medium degree.

The study also showed that the absence of statistically significant differences, attributable to the variables: (gender and experience) the results also suggest that there are statistically significant differences due to the variable of scientific qualification in favor of the postgraduate studies. The study recommends reviewing the development of the Arabic language books for the primary stage by the management of books and school curricula in the Ministry of Education, and includes psychological foundations, in a deeper, and to a high degree.

Saudi Arabia and Hamouda (2016) conducted a study aimed at revealing the extent to which the books of Islamic education for the first three grades of the psychological bases are considered from the point of view of the grade teachers in Jordan, the study sample consisted of (100) grade teachers in Tafila governorate, in the 2015-2016 semester, the study used the descriptive approach, the results of the study were as follows: The religious dimension obtained the highest arithmetic mean, with high estimation, the lowest was the mental dimension, having obtained the lowest average arithmetic, and was also with high estimate, the study also showed that there are no statistically significant differences, due to the variables (scientific qualification, experience, grade) or interaction between them.

Joan et al., (2016) conducted a study on the psychological principles of learners, from kindergarten to twelfth grade. The study aimed to identify twenty principles of psychology, related to learning and teaching, within the classroom from the point of view of psychologists at the American Psychological Association (ApA), the study found the relationship between these principles and teaching practices within the classroom, and the implications of these principles and their obvious effects on students' achievement and motivation towards the learning process.

Mekhemer (2013) conducted a study aimed at revealing the psychological, social and educational needs of talented students from their point of view, and their teachers in Gaza City, and to know the differences in psychological, social and educational needs, between the views of male and female teachers and students and talented students, where the researcher used descriptive analytical approach, the study sample reched (50) teachers and (100) students, were selected in a simple random way, and the study reached the following results:

- The existence of many of the psychological, social, and mental needs, needed by talented people, represented by Training, guidance, and the absence of significant differences between the response of male and femal teachers , students .

Bakr (2013) conducted a study aimed at revealing the psychological needs and knowledge of their differences (males and females) in a sample of students of the Faculty of Science and Arts, Batrabel, the northern region of Saudi Arabia, where the study sample consisted of (60) male and female students.

The researcher used the psychometric scale (Deci and Ryan, 1999) Arabization and classification of Mohammed Alwan, and the study found that there are differences in the averages of psychological needs, and the results showed: There are differences of statistical significance in the direction of males in the psychological needs of the needs of independence, the need for belonging was more pronounced in females.

The Hamdna study (2011) aimed to reveal the extent to which the Arabic language books in the first four grades in the basic education stage in Jordan were considered for the characteristics of the developmental students from the point of view of the teachers in the Directorate of Education North West Badia to Mafraq Governorate, the sample of the study was 100 teachers. The study concluded that there were no statistically significant differences in the fields of study, due to the variables (gender, educational qualification, teaching experience).

Al-Sharari (2007) conducted a study aimed at revealing the degree of observance of the books of Islamic education for the upper elementary stage - Fourth, fifth and sixth grade primary - psychological foundations, the study community is one of the books of Islamic education for the upper stage in the Kingdom of Saudi Arabia, and reached the following results: The higher the level of the classroom, the degree to which the contents of the psychological bases have been taken into account in the book of Islamic education has increased and to a high degree, with a percentage of (45\%), and took into account the implications of psychological foundations in the field of Islamic faith to a high degree, and the study showed the distribution of the contents of the psychological foundations in each area of the three areas, at the level of the stage as a whole.

Abu Rahma (2006) conducted a study aimed at knowing the extent to which the Arabic language books in the first three grades in Jordan included the psychological foundations of the curriculum, where the researcher used the descriptive approach in his analysis of the content, and the sample of the study consisted of books of our Arabic language, scheduled for the first three basic classes in Jordan, the study concluded that the books of our Arabic language in Jordan included (48) basis, which fall under six areas: Mental growth, physical, linguistic, social, 
emotional and religious. And repeated in the textbooks Sample Study: (1398) times, and that the distribution of these bases in the books was not balanced.

The Arabic language book for grades 8 and 10 showed interest in the skill of listening and their relationship with other skills, and a clear interest in the use of technology and use it to learn Arabic and to teach it.

\section{Comment on previous studies}

Studies differ in their objectives, and tools and in the articles dealt with, this study came to coincide with the following studies in its subjects:

1. Al-Rifa'i Study (2018), which came to reveal the degree to which Arabic language books are considered for the basic stage of the psychological foundations from the point of view of its teachers in Tafileh Governorate.

2. Al-Rifa'i Study (2018), which came to reveal the degree to which Arabic language books are considered for the basic stage of the psychological foundations from the point of view of its teachers in Tafileh Governorate.

3. The study of Hamadna (2011), Which came to reveal the extent to which Arabic books are considered for the first four grades in Jordan, for the characteristics of developmental students, from the point of view of teachers.

4. The Abu Rahma study (2006), which came to reveal the extent of the inclusion of Arabic language books for the first three grades of the psychological foundations of the curriculum.

But the most important thing that distinguishes this study from previous studies is that it aims to reveal the level of representation of Arabic language books for the basic stage in Jordan for the psychological foundations of the curriculum From the point of view of teachers in Ma'an, which is being taught for the first time after being amended and developed in the schools of the Hashemite Kingdom of Jordan last year: 2017/2018, in accordance with the decision of the Ministry of Education, No. 36/2017, dated 17/1/2017, pursuant to the decision of the Education Council No. 89/2016, according to the researcher knowledge.

This study has benefited from previous studies, in the background of the study, the methodology followed, the study tool, and the statistical procedures followed.

\section{Method and procedures}

Methodology of the study

The researcher used in the treatment of this study and to answer of its questions, the descriptive approach, which is based on describing and interpreting what exists, in order to determine the degree of observance of the Arabic language books for the basic stage in Jordan, for the psychological foundations, from the point of view of its teachers, and how this affects some of their personal variables.

\section{Population of the study}

The study community consist of all male and female teachers who are teaching the minimum basic stage in the directorates of education in Ma'an, for the academic year 2018/2019, the total number of members of the study community was 164 male and female teachers , of them: (55) male and female teachers in the Directorate of the southern Badia, and (35) male and female teachers in the Directorate of Education Ma'an, (40) male and female teacher from the Directorate of Education Brigade Petra and (34) from the Directorate of Education, Shubak Brigade.

\section{The study sample}

The sample of the study consisted of (110) male and female teachers, who are teaching the minimum basic stage in the directorates of education in the governorate of Ma'an, (Directorate of Education of Ma'an) Directorate of Education of the Southern Badia, Directorate of Education of Petra Brigade, Directorate of Education of Al-Shubak Brigade), were selected from the study population, in a randomized stratified manner, and by (45\%), this percentage reflects the nature of the study population, the sample was selected according to the study variables, as shown in the following table: 
Table 1: Distribution of the study sample

\begin{tabular}{lllllllllll}
\hline $\begin{array}{l}\text { Directorate } \\
\text { of } \\
\text { education }\end{array}$ & $\mathbf{N}$ & Gender & \multicolumn{3}{c}{ Scientific qualification } & \multicolumn{3}{c}{ Experience } \\
Male & Female & Ba $\begin{array}{l}\text { Bachelor } \\
+ \\
\text { Diploma }\end{array}$ & Postgraduate & $\mathbf{1 - 5}$ & $\begin{array}{l}\mathbf{6 -} \\
\mathbf{1 0}\end{array}$ & $>\mathbf{1 1}$ \\
\hline $\begin{array}{l}\text { Ma'an area } \\
\text { Southern }\end{array}$ & 30 & 15 & 15 & 18 & 8 & 4 & 8 & 12 & 10 \\
Badia & 45 & 20 & 25 & 25 & 10 & 10 & 10 & 15 & 20 \\
Petra & 20 & 8 & 12 & 13 & 4 & 3 & 6 & 8 & 6 \\
Shobak & 15 & 8 & 7 & 9 & 3 & 3 & 5 & 7 & 3 \\
\hline Total & $\mathbf{1 1 0}$ & 51 & 59 & 65 & 25 & 20 & 29 & 42 & 45 \\
\hline
\end{tabular}

\section{The study variables}

The study included three independent variables, and one dependent variable:

First: The independent variables: including

- $\quad$ Gender, and has two levels: male, female.

- Scientific qualification: it has three levels: Bachelor, Post-graduate Diploma.

- Teaching experience, and has three levels: less than (5) years, (5-10) years, (11 years

and more).

Second: The dependent variable: The estimates of male and female teachers of Arabic language for the lower basic stage of the level of representation of the books of the psychological foundations of the curriculum, through the domains measured by the questionnaire.]

\section{Study tool}

The researcher developed a questionnaire to collect data from the sample of the study to answer its questions and was adopted in the preparation of the questionnaire on the previous literature, such as the study (Al-Rufu'i, 2018) and the study (Saudi and Hamouda, 2016), and study of (Al Fayoumi, 2013), and study (Samir, 1994), and the study tool consists of two parts: First: instructions to fill the questionnaire, and the second: the paragraphs of the questionnaire and its areas, and their total number: (54) paragraph distributed on the six areas of the questionnaire: (Linguistic, mental, social, physical, religious, and emotional), with (9) paragraphs for each field.The response to the paragraphs and areas of the questionnaire, according to the five-dimensional Likert scale (very high, high, medium, low, very low), according to the numbers $(1,2,3,4,5)$ respectively, so that the number $(5)$ represents the highest estimate of the paragraph and the number (1) Minimum estimate of paragraph.

\section{Validity of the tool}

To verify the validity of the tool prepared by the researcher; to serve for the purpose of the study, the researcher developed a classification of the psychological foundations of the subject of the study, and formed in its initial form of (62) paragraph, distributed over six main areas: (Linguistic, mental, physical, social, emotional, and religious), the researcher then presented them to a group of arbitrators, in order to express their opinion, about the validity of the content of the classification, and the extent of belonging to each of its paragraphs, for the field under which it falls, its appropriateness and the correctness of its language formulation, and after reviewing their observations, the researcher make the appropriate adjustments, taking all the notes made by the arbitrators, thus, the tool is in its final form of (54) paragraphs, spread over six key areas.

\section{Reliability of the tool}

To ensure the reliability of the tool, the researcher distributed the questionnaire on a survey sample from the study community, and outside the sample of the study, which consisted of (15) male and female teachers , using (Alpha 
Kronbach equation), the stability coefficient was calculated for each of the six fields of study, and for the whole questionnaire, where the stability coefficient of the tool (0.98) stability coefficient was calculated between the results of the two applications, with a time difference of two weeks where it reached (0.90) it is an acceptable value for the purposes of the study, and can be trusted, and the values of the consistency coefficient of internal consistency ranged between $(0.82-0.98)$. The stability coefficient was between $(0.84-0.89)$, as shown in the following table:

Table (2): Reliability coefficients of the domains of the questionnaire

\begin{tabular}{llll}
\hline Domain & Items & $\begin{array}{l}\text { Reliability coefficient of } \\
\text { internal consistency }\end{array}$ & $\begin{array}{l}\text { Reliability } \\
\text { coefficient } \\
\text { reliability }\end{array}$ \\
\hline Linguis domain & 9 & 0.82 & 0.85 \\
Mental domain & 9 & 0.87 & 0.84 \\
Social domain & 9 & 0.88 & 0.85 \\
Physical domain & 9 & 0.94 & 0.86 \\
Religuios domain & 9 & 0.90 & 0.89 \\
Emotional domain & 9 & 0.98 & 0.89 \\
\hline Total & $\mathbf{5 4}$ & $\mathbf{0 . 9 8}$ & $\mathbf{0 . 9 0}$ \\
\hline
\end{tabular}

\section{Statistical Treatment}

1. Using (Carnbach alpha) equation; to extract the coefficient of reliability of internal consistency, for the domains of the questionnaire.

2. Using (Pearson) correlation coefficient; to extract reliability coefficient for the domains of the questionnaire.

3. The extraction of mathematical averages, and standard deviations; to determine the level of representation of Arabic language books for the lower basic stage, the psychological foundations of the curriculum from the point of view of teachers in Ma'an Governorate.

4. One Way ANOVA; to examine the effect of some independent variables (gender, experience, qualification) on the level of representation of Arabic language books, of the psychological foundations of the curriculum from the point of view of its teachers.

5. Tukey HSD for post comparisons; to find differences in the level of representation of Arabic language books for the lower basic stage, from the point of view of its teachers, according to the scientific qualification variable.

6. Using (T-Test); to compare between the two groups: male and female.

7. In order to judge the value of the arithmetic mean in three categories: (high, medium, low), the range between the highest gradient and the lowest gradient of the questionnaire is $(5-1=4)$ was split on the number of distribution categories: (1-2.33) low, (2.34-3.67) medium and (3.68-5) high.

\section{Results of the Study}

Results related to the first question:"What is the level of representation of Arabic language books for the basic stage in Jordan for the psychological foundations of the curriculum from the point of view of teachers in the governorate of Ma'an?"

To answer this question, the arithmetical averages, standard deviations, ranks, and levels of teacher responses to the study instrument were calculated by each of the six instrument domains. Table 4 shows the arithmetical averages, standard deviations, and ranks for all six fields of study. Tables (4-9) show descriptive statistics of teacher responses to the study tool for each of the six domains: 
Table (3): means, standard deviations and ranks for all the six domains of study

\begin{tabular}{llllll}
\hline N & Domain & Mean & $\begin{array}{l}\text { Standard } \\
\text { deviation }\end{array}$ & Rank & Level \\
\hline 1 & Linguistic & 3.71 & 0.93 & 1 & High \\
2 & Mental & 3.45 & 0.89 & 5 & Moderate \\
3 & Social & 3.47 & 0.95 & 4 & Moderate \\
4 & Physical & 3.46 & 0.97 & 6 & Moderate \\
5 & Religious & 3.58 & 1.03 & 2 & Moderate \\
6 & Emotional & 3.55 & 0.88 & 3 & Moderate \\
\hline- & Total & 3.53 & 0.94 & -- & Moderate \\
\hline
\end{tabular}

Table 3 shows that the mathematical averages for all fields ranged from $(3.71$ - 3.46), where we find all domains in the moderate level, except for the linguistic domain, which reached a high level with the highest rank with an average of (3.71), followed by the religious domain with a mean of (3.58), then the emotional domain with a mean of (3.55), then followed by the social domain with a mean of (3.47), followed by the mental domain, with a mean of (3.45), the most recent was the physical domain, and with an arithmetic average of (3.46).

Table (4): means, standard deviations and ranks of linguistic domain

\begin{tabular}{llllll}
\hline $\mathbf{N}$ & Item & Mean & $\begin{array}{l}\text { Standard } \\
\text { deviation }\end{array}$ & Rank & Level \\
\hline 1 & $\begin{array}{l}\text { Books help students acquire language vocabulary } \\
\text { that helps them adapt to everyday life }\end{array}$ & 3.82 & 0.84 & 3 & High \\
2 & $\begin{array}{l}\text { Books develop the correct expression skills for } \\
\text { students' needs and observations. }\end{array}$ & 3.67 & 0.78 & 7 & High \\
3 & $\begin{array}{l}\text { Books show some common language errors. } \\
4\end{array}$ & 3.04 & 1.22 & 9 & Moderate \\
5 & $\begin{array}{l}\text { Books develop students' speaking skills. } \\
\text { Books develop students' proficiency in writing. }\end{array}$ & 3.94 & 0.87 & 2 & High \\
6 & $\begin{array}{l}\text { Books develop students' listening skills and } \\
\text { commitment to ethics. }\end{array}$ & 4.08 & 0.83 & 4 & High \\
7 & $\begin{array}{l}\text { Books promote positive attitudes towards free } \\
\text { reading. }\end{array}$ & 3.33 & 1.16 & 8 & Moderate \\
8 & $\begin{array}{l}\text { Books develop the skills of dialogue and } \\
\text { discussion among students. }\end{array}$ & 3.78 & 0.86 & 6 & High \\
9 & $\begin{array}{l}\text { Books help to use the correct language. } \\
\text { Total }\end{array}$ & 3.75 & 0.87 & 5 & High \\
\hline
\end{tabular}

From the table (4), we can see that the linguistic domain came at a high level, where the arithmetical averages for all its items ranged between (3.040 and (4.08). All of them reached the high level, except for item (7) and item (3), it came at a medium level, item (6) which states (books develop the skill of listening to students and commitment to ethics) ranked first, and the lowest items rank is item (3) (the books show some common language errors). 
Table (5): means, standard deviations and ranks of the mental domain

\begin{tabular}{|c|c|c|c|c|c|}
\hline $\mathbf{N}$ & Item & Mean & $\begin{array}{l}\text { Standard } \\
\text { deviation }\end{array}$ & Rank & Level \\
\hline 1 & $\begin{array}{l}\text { Books correspond to students' mental abilities } \\
\text { (conclusion, analysis, synthesis). }\end{array}$ & 3.76 & 0.71 & 1 & High \\
\hline \multicolumn{6}{|l|}{2} \\
\hline & Students develop self-knowledge. & 3.31 & 0.85 & 7 & Moderate \\
\hline 3 & $\begin{array}{l}\text { Books achieve balance and integration between } \\
\text { language branches. }\end{array}$ & 3.60 & 0.80 & 3 & Moderate \\
\hline 4 & $\begin{array}{l}\text { Books confirm the rejection of the blind } \\
\text { imitation. }\end{array}$ & 3.18 & 1.04 & 9 & Moderate \\
\hline 5 & Books develop students' research skills. & 3.47 & 0.84 & 6 & Moderate \\
\hline 6 & Books promote students' competition. & 3.48 & 0.90 & 5 & Moderate \\
\hline 7 & Books provide a positive learning environment. & 3.56 & 0.80 & 4 & Moderate \\
\hline 8 & $\begin{array}{l}\text { Books display topics in a sequential and } \\
\text { interrelated manner. }\end{array}$ & 3.76 & 0.87 & 2 & High \\
\hline 9 & Books develop problem solving skills. & 3.30 & 0.92 & 8 & Moderate \\
\hline - & Total & 3.49 & 0.88 & -- & Moderate \\
\hline
\end{tabular}

In terms of table (5), the mental domain came in the medium level, with a mean of (3.49), where the means of all its items ranged from (3.76 - 3.18), the highest rank was for item (1) with a mean of (3.76), the books correspond to the students' mental abilities (conclusion, analysis, and synthesis), which came at the highest level, and rank (1), the lowest rank was item (4), (the books confirm the rejection of the blind imitation), with a mean of (3.18), and rank (9).

Table (6): means, standard deviations and the ranks of the social domain

\begin{tabular}{|c|c|c|c|c|c|}
\hline $\mathbf{N}$ & Item & Mean & $\begin{array}{l}\text { Standard } \\
\text { deviation }\end{array}$ & Rank & Level \\
\hline \multicolumn{6}{|l|}{1} \\
\hline & $\begin{array}{l}\text { Books urge social responsibility towards school, } \\
\text { community and friends. }\end{array}$ & 3.62 & 0.87 & 2 & Moderate \\
\hline \multicolumn{6}{|l|}{2} \\
\hline & Books develop a sense of parental value. & 3.77 & 0.95 & 1 & High \\
\hline 3 & $\begin{array}{l}\text { Books promote the value of cooperation between } \\
\text { school and home. }\end{array}$ & 3.55 & 0.97 & 3 & Moderate \\
\hline 4 & $\begin{array}{l}\text { Books encourage students to participate in daily work } \\
\text { at school and at home. }\end{array}$ & 3.50 & 0.96 & 5 & Moderate \\
\hline 5 & Books help students adapt to school and colleagues. & 3.41 & 0.89 & 6 & Moderate \\
\hline 6 & Students are urged to avoid bad companions. & 3.33 & 1.02 & 8 & Moderate \\
\hline 7 & $\begin{array}{l}\text { Books emphasize respect for people with special } \\
\text { needs }\end{array}$ & 3.23 & 1.08 & 9 & Moderate \\
\hline 8 & Books promote tolerance and non-violence. & 3.61 & 0.95 & 4 & Moderate \\
\hline 9 & $\begin{array}{l}\text { Students are directed towards social problems and } \\
\text { solve them peacefully. }\end{array}$ & 3.36 & 0.96 & 7 & Moderate \\
\hline - & (20) & 3.48 & 0.97 & -- & Moderate \\
\hline
\end{tabular}


Table (6) shows that the social domain came in the moderate level, where the means for all its items ranged from (3.77 to 3.23) and all came with a moderate level. Item (2): (books develop the sense of parental value), ranked first, with a mean of (3.77), and the lowest items' rank is item (3): (books confirm respect for people with special needs).

Table (7): means, standard deviations and ranks of the physical domain

\begin{tabular}{|c|c|c|c|c|c|}
\hline $\mathbf{N}$ & Item & Mean & $\begin{array}{l}\text { Standard } \\
\text { deviation }\end{array}$ & Rank & Level \\
\hline \multicolumn{6}{|c|}{ 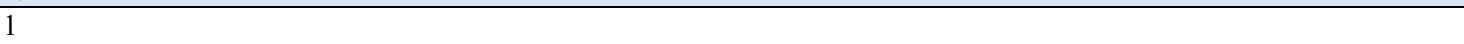 } \\
\hline & Books promote the need for sports & 3.28 & 1.02 & 9 & Moderate \\
\hline \multicolumn{6}{|l|}{2} \\
\hline & The books teach students how to prevent disease & 3.41 & 0.98 & 6 & Moderate \\
\hline 3 & $\begin{array}{l}\text { Books develop healthy habits for students in food and } \\
\text { drink }\end{array}$ & 3.42 & 1.05 & 5 & Moderate \\
\hline 4 & Books develop good moral values. & 3.71 & 0.98 & 1 & High \\
\hline 5 & $\begin{array}{l}\text { Books take into consideration the growth characteristics } \\
\text { of students. }\end{array}$ & 3.51 & 0.83 & 3 & Moderate \\
\hline 6 & $\begin{array}{l}\text { The books offer classes that develop healthy habits for } \\
\text { students. }\end{array}$ & 3.52 & 0.82 & 2 & Moderate \\
\hline 7 & $\begin{array}{l}\text { Books reinforce the need for attention to the general } \\
\text { appearance }\end{array}$ & 3.39 & 0.97 & 7 & Moderate \\
\hline 8 & $\begin{array}{l}\text { The books emphasize the importance of students' } \\
\text { interest in their cleanliness. }\end{array}$ & 3.48 & 0.93 & 4 & Moderate \\
\hline 9 & $\begin{array}{l}\text { Books promote the importance of manual work for } \\
\text { students. }\end{array}$ & 3.29 & 1.05 & 8 & Moderate \\
\hline - & Total & 3.44 & 0.96 & -- & Moderate \\
\hline
\end{tabular}

Note from Table (7) that the physical domain came in the moderate level, where the means, for all its items, ranged from (3.71 - 3.28) and all came in the moderate level. Item (4) "books develop the correct moral values", ranked first, with a mean of (3.71), and the lowest rank was for item (1), (books reinforce the need for sports) with a mean of (3.28).

Table (8): means, standard deviations and the ranks of the religious domain

\begin{tabular}{|c|c|c|c|c|c|}
\hline $\mathbf{N}$ & Item & Mean & $\begin{array}{l}\text { Standard } \\
\text { deviation }\end{array}$ & Rank & Level \\
\hline \multicolumn{6}{|c|}{1} \\
\hline & Books help students appreciate tolerance, moderation. & 3.90 & 0.78 & 1 & High \\
\hline 2 & $\begin{array}{l}\text { To encourage appreciation, respect and preservation of } \\
\text { religious texts. }\end{array}$ & 3.62 & 0.88 & 4 & Moderate \\
\hline 3 & $\begin{array}{l}\text { Development of faith trends towards the concepts of Islamic } \\
\text { education. }\end{array}$ & 3.57 & 0.92 & 6 & Moderate \\
\hline 4 & Encourage students to practice Islamic ethics. & 3.71 & 1.01 & 2 & High \\
\hline 5 & $\begin{array}{l}\text { The curriculum promotes imitating the Prophet (peace and } \\
\text { blessings of Allaah be upon him). }\end{array}$ & 3.62 & 1.10 & 3 & Moderate \\
\hline 6 & $\begin{array}{l}\text { Provide students with practices that help build ethical and } \\
\text { religious values. }\end{array}$ & 3.60 & 1.06 & 5 & Moderate \\
\hline 7 & Invitation to participate in various religious events. & 3.41 & 1.07 & 8 & Moderate \\
\hline 8 & Encourage students to perform and adhere to worship. & 3.46 & 1.13 & 7 & Moderate \\
\hline 9 & $\begin{array}{l}\text { The books develop appreciation of the efforts of Muslim } \\
\text { scholars. }\end{array}$ & 3.22 & 1.09 & 9 & Moderate \\
\hline- & Total & 3.57 & 1.02 & -- & Moderate \\
\hline
\end{tabular}


From table 8 , we can see that the religious domain came in the moderate level, where the means for all its items ranged from (3.93-3.22). All of which came in the moderate level, except for item (1), (books help students to appreciate the value of tolerance, and moderation), came with a high level, with a mean average of (3.93) and first rank, and item (6), (the students develop the national spirit of the students) also came with a high level with a mean of (3.92). The lowest items' the rank was item (9) the books develop appreciation of the efforts of Muslim scholars, with a mean of (3.22) and rank 9.

Table (9): means, standard deviations and ranks of emotional domain

\begin{tabular}{|c|c|c|c|c|c|}
\hline $\mathbf{N}$ & Item & Mean & $\begin{array}{l}\text { Standard } \\
\text { deviation }\end{array}$ & Rank & Level \\
\hline \multicolumn{6}{|l|}{1} \\
\hline & Books develop positive attitudes towards Arabic. & 3.75 & 0.77 & 2 & High \\
\hline \multicolumn{6}{|l|}{2} \\
\hline & Books focus on self-realization. & 3.40 & 0.89 & 7 & Moderate \\
\hline 3 & Books achieve positive dealing with others. & 3.55 & 0.94 & 4 & Moderate \\
\hline 4 & Books help to provide a safe educational environment. & 3.41 & 0.87 & 8 & Moderate \\
\hline 5 & Books help satisfy human needs such as love and security. & 3.48 & 0.89 & 6 & Moderate \\
\hline 6 & Books develop the national spirit of students. & 3.95 & 0.89 & 1 & High \\
\hline 7 & Books promote charitable work and helping others & 3.56 & 0.87 & 5 & Moderate \\
\hline 8 & Books develop a spirit of interest in the interests of others. & 3.35 & 0.93 & 9 & Moderate \\
\hline 9 & Books develop positive thinking among students. & 3.62 & 0.78 & 3 & Moderate \\
\hline - & Total & 3.57 & 0.89 & -- & Moderate \\
\hline
\end{tabular}

From the table (9), we find that the emotional domain came in the moderate level, where the means for all its items ranged between (3.92-3.37). All of them came in the moderate level, except item (1) and item (6), where they came high level, and the most rank, was item (1), with an average of (3.92), (the books develop the national spirit of the students), and the lowest rank is item (8), (The books develop the spirit of interest with the interests of others), with an average of (3.37).

Results relating to the second question:"Are there statistically significant differences at the level of significance $(\alpha \leq 0.05)$, in the views of Arabic language teachers for the lower basic stage in their estimate of the level of representation of Arabic language books for the basic stage of the psychological foundations of the curriculum according to the gender variable?"

To answer this question, means and standard deviations of teacher responses to the study instrument were first calculated according to the gender variable. Table 10 shows the arithmetical averages and standard deviations according to the gender variable.

Table (10): means and standard deviations according to the gender variable

\begin{tabular}{lll}
\hline Gender & Mean & Standard deviation \\
\hline Males & 3.51 & 0.94 \\
\hline Females & 3.56 & 0.95 \\
\hline Total & $\mathbf{3 . 5 3}$ & $\mathbf{0 . 9 4}$ \\
\hline
\end{tabular}


Table (10) shows that there are apparent differences in the mean to respond to all areas of the study instrument,the average response rate of females was (3.56), higher than that of males (3.51), to find out the statistically significance of these differences, (T-Test) of the differences between two groups was conducted. Table (11) shows the results of the T-Test of differences between two groups of the gender variable.

Table (11): T-Test results for differences between two groups of the gender variable

\begin{tabular}{llllll}
\hline Gender & Mean & $\begin{array}{l}\text { Standard } \\
\text { deviation }\end{array}$ & T value & Df & Sig \\
\hline Males & 3.51 & 0.94 & & & \\
Females & 3.56 & 0.95 & 0.417 & 81 & 0.678 \\
\hline
\end{tabular}

Table (11) shows that there are no statistically significant differences at the level of $(0.05)$ between the male and female groups, where the value of " $\mathrm{T}$ " was (0.417) and the level of significance: $(0.678)$, which is greater than (0.05).

Results related to the third question: Are there statistically significant differences at the level of significance $(\alpha \leq 0.05)$, in the views of Arabic language teachers for the lower basic stage in their estimate of the level of representation of Arabic language books for the basic stage of the psychological foundations of the curriculum according to the scientific qualification variable?"

To answer this question, arithmetical averages and the standard deviations of teachers' responses to the study instrument were first calculated according to the scientific qualification variable. Table 12 shows the arithmetical averages and the standard deviations according to the scientific qualification variable.

Table (12): means and standard deviations according to the variable of scientific qualification

\begin{tabular}{lll}
\hline Scientific qualification & Mean & Standard deviation \\
\hline Bachelor & 3.43 & 0.94 \\
\hline Diploma after Bachelor & 3.62 & 0.95 \\
\hline Postgraduate & 3.87 & 0.93 \\
\hline Total & $\mathbf{3 . 5 3}$ & $\mathbf{0 . 9 4}$ \\
\hline
\end{tabular}

Table (12) shows that there are apparent differences in the arithmetic mean to respond to all areas of the study instrument, the highest average response was for the teachers in the postgraduate group, with a mean of (3.87), followed by the teachers in the post-bachelor diploma group, with a mean of (3.62), and finally the teachers in the bachelor group, with an average of (3.43), i.e, the average response on the study tool, increases by increasing the scientific qualification. To find out the significance of these differences statistically, one way ANOVA was performed; table (13) shows the results of One Way ANOVA analysis, according to the scientific qualification variable. 
Table (13): Results of the One Way ANOVA analysis according to the scientific qualification variable

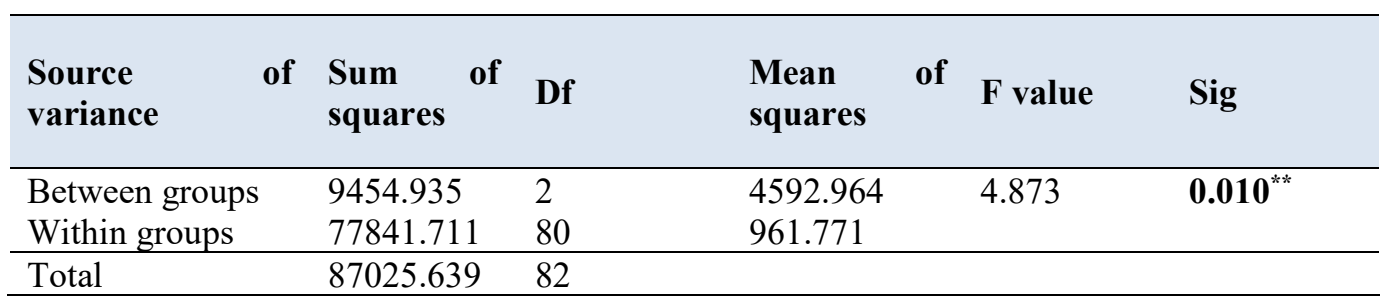

Table (13) shows statistically significant differences at the level of $(0.05)$ between the three groups of teachers, according to the scientific qualification variable, where the value of " $F$ " was (4.868), at a significant level: (0.010), which is greater than $(0.05)$, to determine the nature of these differences and for any of the groups, the Tukey HSD for the post-comparisons was performed. Table (14) shows the results of the Tukey HSD, for the scientific qualification variable.

Table (14): Results of the Tukey HSD for the scientific qualification variable

\begin{tabular}{|c|c|c|c|c|}
\hline $\begin{array}{l}\text { Scientific } \\
\text { qualification }\end{array}$ & Scientific qualification & Average differences & Standard error & Sig \\
\hline \multirow{2}{*}{ Bachelor } & Diploma after bachelor & -11.2709 & 7.91145 & 0.33 \\
\hline & Postgraduate & $-32.42549^{*}$ & 10.72646 & 0.009 \\
\hline \multirow{2}{*}{ Diploma after } & Bachelor & 11.27094 & 7.91045 & 0.33 \\
\hline & Postgraduate & -21.1546 & 11.82768 & 0.18 \\
\hline \multirow{2}{*}{ Postgraduate } & Bachelor & $32.42549^{*}$ & 10.72546 & 0.009 \\
\hline & Diploma after bachelor & 21.15455 & 11.82768 & 0.18 \\
\hline
\end{tabular}

Table (14) shows that statistically significant differences were found between the undergraduate and graduate groups in favor of the postgraduate group, the level of significance was (0.009), which is less than (0.05), there were no differences between the bachelor and postgraduate courses, where the level of significance was $(0.33)$, and the diploma after bachelor groups and postgraduate studies, where the level of significance was $(0.18)$.

Results related to the fourth question:"Are there statistically significant differences at the level of significance $(\alpha \leq 0.05)$ in the views of the teachers of the Arabic language for the lower basic stage in their estimation of the level of representation of Arabic language books of the psychological foundations of the curriculum according to the experience variable?"

To answer this question, calculation of the arithmetical averages and the standard deviations of the teachers' responses to the study instrument were first calculated according to the variable of experience. Table 15 shows the arithmetical averages and the standard deviations according to the experience variable. 
Table (15): means and the standard deviations according to the variable of experience

\begin{tabular}{lll} 
Scientific qualification & Mean & Standard deviation \\
\hline $\mathbf{1 - 5}$ & 3.47 & 0.98 \\
\hline $\mathbf{6 - 1 0}$ & 3.54 & 0.94 \\
\hline $\mathbf{1 1}$ and more & 3.55 & 0.95 \\
\hline Total & $\mathbf{3 . 5 3}$ & $\mathbf{0 . 9 4}$ \\
\hline
\end{tabular}

Table (15) shows that there are apparent differences in the arithmetic mean to respond to all domains of the study instrument,the highest response rate for teachers with 11 years experience and above was an average of (3.55), followed by teachers with (6-10) years with an average of (3.54), and finally teachers whose experience (1-5 years) with an average of (3.47), i.e, the average response to the study tool increases with the increase in the number of years of teaching experience. To find out the significance of these differences statistically, One-Way ANOVA) analysis of variance was conducted; table (16) shows the results of One Way ANOVA according to the variable of experience:

Table (16): Results of One Way ANOVA analysis according to experience variable

\begin{tabular}{|c|c|c|c|c|c|}
\hline $\begin{array}{l}\text { Source } \\
\text { variance }\end{array}$ & $\begin{array}{l}\text { Sum of } \\
\text { squares }\end{array}$ & Df & $\begin{array}{l}\text { Mean of } \\
\text { squares }\end{array}$ & F value & Sig \\
\hline $\begin{array}{l}\text { Between groups } \\
\text { Within groups }\end{array}$ & $\begin{array}{l}196.689 \\
89807.283\end{array}$ & $\begin{array}{l}2 \\
80\end{array}$ & $\begin{array}{l}97.842 \\
1125.598\end{array}$ & 0.087 & 0.920 \\
\hline Total & 90002.982 & 82 & & & \\
\hline
\end{tabular}

Table (16) shows that there are no statistically significant differences at the level of (0.05) between the groups of teachers, according to the variable of experience, where the value of "F" was $(0.087)$ with a significance level of (0.920), which is greater than (0.05).

\section{Discussion of findings and recommendations:}

The aim of this study is to investigate the degree of observance of the Arabic language books for the minimum basic stage, for the psychological foundations from the point of view of male and female teachers, and the extent of the impact of some variables, and the results of this study will be discussed according to the study's questions.

Discussion of the results related to the first question: "What is the level of representation of Arabic language books for the lower elementary stage in Jordan, psychological foundations of the curriculum from the point of view of their teachers in the Governorate of Ma'an?"

Through the presentation of the results, we note that all six areas of study were middle class, and with an arithmetic mean ranged between: (3.57-3.44), with the exception of the linguistic field, which came at a high level, with an average of (3.68), and the researcher attributed the advent of the linguistic field to a high degree, to the following:

- Teachers are better able to respond to the linguistic field as specialists and have academic qualifications in this field.

The rest of the fields, came to the middle class, and attributed the researcher to: 
- The new books are applied in the schools of the Ministry of Education, for the first time last year, according to the knowledge of the researcher.

- The study sample did not receive sufficient training programs to deal with textbooks.

After reviewing the arithmetical averages and standard deviations of all paragraphs in each area of study, we find the following:

\section{First: The linguistic domain:}

Arithmetic averages of all paragraphs ranged from: (06/04 to 02/03), which are values ranged between the high and average, and topped the paragraph: (6) It is :( The books develop students' listening skills and commitment to ethics) ranked first, high degree, with an arithmetic mean: (4.06), this is a sign that the Arabic language books develop the skill of listening to students, and the researcher attributed this to the importance of this skill, in the construction of linguistic and cognitive stock, and to provide the ability to perform a behavior with high efficiency, such as reading to students. Paragraph (3) is: (the books show some common language errors) with a Middle-class and rank last and with an arithmetic mean: (3:02), The researcher attributed this to that the teacher corrects errors during the classroom situation, and there is no need to include them in the curriculum, and that the responsibility to follow the students and correct their language errors, is the responsibility of all teachers of the detective.

\section{Second: The mental domain:}

The averages for all the paragraphs ranged from (3.76 to 3.18), all of which came in the intermediate grade, except for paragraph (1), (the books correspond to the students' mental abilities - conclusion, analysis, composition) came in first place, and high degree, with an average arithmetic: (3.76), the researcher attributed that, that the books of the Arabic language, taking into account the mental abilities of students, and urges them to think and apply the mind, where the study agreed in this field with the study of Al-Sameer (1994), paragraph (4): (The books confirm the rejection of the blind tradition), in the intermediate grade, and rank: (9), with an arithmetic mean: (3.18), and the researcher attributed this to:

- All the media, from satellite stations, websites and social media, covering this area, and is satisfied with family awareness, and extracurricular activities within the walls of the school.

\section{Third: Social domain:}

Arithmetic averages for all paragraphs ranged from: (3.75-3.20), all of which were middle-class, with the exception of paragraph (2), (Books develop the sense of value of parents), came with high degree, and this is a sign that the books of the Arabic language emphasizes the sense of the value of parents, and their obedience, the researcher attributed that, that the books take into account the philosophical and religious foundations, and the books represent the integrative curriculum, and the unity of scope for all school curricula. Paragraph (7), (The books confirm the respect of people with special needs), middle class, and last rank, with an average of (3.20), the researcher attributes this to the policy of the Ministry of Education to integrate students with special needs into their students' peers. This section is covered by the guiding lessons given by the school's educational counselor and through the school's management guidelines and class supervisors.

\section{Fourth: The physical domain:}

It was noted that all the averages of the physical field ranged from $(3.71-3.28)$, where paragraph topped the No. (4) : ( Books develop good moral values) ranked first, to a high degree, with an arithmetic mean: (3.71). The researcher attributes this to the importance of these values in the life of the individual, which is to please God Almighty, and the development of the values of compassion and cooperation, and the good relationship with parents, and that it achieves happiness for the individual in this world and the Hereafter. Paragraph (1), (Books reinforce the need for the practice of sports), the last rank, and the middle degree, and the average arithmetic: (3.28), the researcher attributed this to: that the curriculum of physical education covers this, and dchool and extracurricular activities achieved this paragraph among students. In general, books urge students to take care of their bodies and to preserve them from diseases. This study is consistent with the study of Al-Rifa'i (2018), Al Saudi and Hawamdeh (2016).

\section{Fifth: Religious domain:}

We note that all paragraphs of the religious sphere, ranging from: (3.93 -3.22), all of which were middle-class, with the exception of paragraph number (1), (Books help to appreciate the value of tolerance, moderation ), where 
it came at the high level, and rank: (1), and with an arithmetic mean: (3.93), and paragraph number (4), came high class as well, rank (2), with an arithmetic mean (3.71), the researcher attributed this to the general policy of the Ministry of Education, which affirms this, based on the Amman Message, and calls for tolerance and distance from extremism, advocacy for dialogue and respect for other religions. Where the paragraph number: (9), (Books develop appreciation of the efforts of Muslim scholars), with a middle grade, and rank: (9), with an arithmetic mean: (3.22), the researcher attributes this to: The curricula of Islamic education, national education and history reinforce this, and this is emphasized through other activities, such as reading, enrichment activities during the educational situation, and in school radio programs. This study is consistent with the study of Al-Rifa '(2018), Al Saudi and Al-Hawamdeh (2016).

\section{Sixth: The emotional domain:}

We found that the arithmetical averages for all emotional domains ranged from (3.92 - 3.37), where it topped the paragraph number: (6), (Books develop the national spirit of students), ranked first, with an average arithmetic: (3.92), and high degree, and the researcher attributed this to strengthening the spirit of belonging to students, and urged them to preserve the soil of the homeland, in light of the conditions experienced by the region, and the need for unity and cohesion to face the dangers. Paragraph (8): (Books develop a spirit of interest in the interests of others), in the last rank and in the middle class, and with an arithmetic mean: (3:37), and the researcher attributed this that the books of Islamic education cover this, as well as lectures, guided by the educational counselor at the school, where we find in general that the books of the Arabic language for the basic stage, the middle class took into account the positive trends towards the Arabic language, to meet the needs of love, security and peace, and to encourage students to think positively.

Discussion of the results related to the second question: "Are there statistically significant differences at the level of significance $(\alpha 0.05)$ in the views of the teachers of the Arabic language for the primary stage in their assessment of the level of representation of Arabic language books for the basic stage of the psychological foundations of the curriculum according to the gender variable?"

To answer this question, the computational averages and standard deviations of teacher responses to the study instrument were initially calculated according to the gender variable. There were apparent differences in the arithmetic mean to respond to all areas of the study instrument. The average response of females was: (3.56) higher than that of males (3.51), to find out the significance of these differences statistically, T-Test was performed for differences between two groups, the results of the T-Test showed differences between two groups of the gender variable. There were no statistically significant differences at the level of significance $(0.05)$ between the male and female groups, where the value of $\mathrm{T}:(0.417)$ and with the level of significance: $(0.678)$, which is greater than $(0.05)$.

The researcher attributes this result to the following:

- That the male and female teachers receive the same knowledge, experience and study plans in higher education institutions.

- Everyone is qualified by the Ministry of Education and subject to the same courses and workshops.

- That the male and female teachers practicing the educational process in the same environments and conditions provided by the Ministry of Education.

Discussion of the results related to the third question: "Are there statistically significant differences at the level of significance $(\alpha 00.05)$ in the views of the teachers of the Arabic language for the primary stage in their assessment of the degree to which the Arabic language books of the psychological bases according to the variable of scientific qualification?"

In order to answer this question, the arithmetical averages and standard deviations of teachers' responses to the study instrument were initially calculated, according to the variable of the scientific qualification, and there were apparent differences in the arithmetic averages to respond to all areas of the study instrument, the highest average response of teachers in the postgraduate group was with an arithmetic mean: (3.87), followed by teachers in the diploma group after bachelor with an average of (3.62), and finally teachers in the bachelor group with an average of (3.43), in other words, the average response to the study tool increases by increasing the scientific qualification. To find out the significance of these differences statistically, one way ANOVA was performed. Where there were significant differences at the level of significance (0.05) between the three groups of teachers according to the variable of scientific qualification, where the value of P: (4.868) and at a significant level: (0.010), which is greater 
than $(0.05)$, to find out the nature of these differences in favor of any of the groups the Tukey HSD test was performed for post-comparisons, the results of the comparisons ( Tukey HSD) were shown for the variable of scientific qualification, there were statistically significant differences in the arithmetic averages between the undergraduate and postgraduate groups in favor of the postgraduate group where the level of significance was: (0.009), which is less than (0.05). There were no differences between the bachelor and postgraduate courses after the bachelor's degree, where the level of significance was 0.33 and the diploma groups after the bachelor's and postgraduate studies where the level of significance: $(0.18)$.

The researcher attributed this to the fact that teachers with high scientific qualifications (Masters and PhD) possess advanced knowledge, expertise and advanced skills. As for the teachers who have a bachelor's degree, there was no impact on their responses to the study tool. The researcher attributes this to their relatively low-level experience, knowledge and skills, with postgraduate qualifications. This applies to teachers who have a diploma after a bachelor's degree, the researcher attributed this to the fact that the majority of them hold postgraduate qualifications in the fields of information technology and school administration, which prevents them from having deep educational experience and skills in the field of curricula and educational work, where the results of this study differed with the study of Saudi and Hawamdeh, (2016), and the study Hammadna, (2011).

Discuss the findings on the fourth question: "Are there statistically significant differences at the level of significance $(\alpha 0.05)$ in the viewpoints of the Arabic language teachers of the lower elementary stage in their assessment of the level of representation of the Arabic language of the psychological bases according to the variable of experience?"

To answer this question, calculation averages and standard deviations of teacher responses to the study instrument were initially calculated according to the variable of experience, there were apparent differences in the arithmetic averages to respond to all areas of the study instrument. The highest response rate was for teachers with 11 years or more experience, with an average of (3.55), followed by teachers whose experience ranged between (6-10) years with an average of (3.54), and finally teachers whose experience ranges from (1-5) years, with an average of (3.47), ie, the average response to the study tool increases with the increase in the number of years of teaching experience. To determine the significance of these differences statistically, one way ANOVA was performed according to the variable of experience.

There were no statistically significant differences at the level of (0.05) between the groups of teachers according to experience. The value of $\mathrm{P}(0.087)$ and the level of significance: $(0.917)$, which is greater than $(0.05)$.

The researcher attributed this to the common circumstances among the members of the study, whether social, educational or academic, and this result is consistent with the study of Al Saudi and Hawamdeh (2016) and the study Hammadneh (2011).

\section{Recommendations}

- The need to review the development of the Arabic language books for the lower basic stage by the management of textbooks and school curricula in the Ministry of Education, and to include the psychological foundations, in a deeper and higher degree.

- Conducting more evaluation studies for the Arabic language books for the lower basic stage to determine the level of representation of the foundations of the other curriculum, whether cognitive, social or philosophical.

\section{References}

Abu Rahma, I. (2006) the degree of consideration of Arabic language books developed in the first three grades in Jordan for the criteria of the psychological foundations of the curriculum. Unpublished Master Thesis, Faculty of Education, Taif University, Saudi Arabia.

Abu Swaylik, M. (1999) the psychological foundations included in the Arabic language books for the fourth, fifth and sixth grades in Jordan, unpublished master thesis. Yarmouk University, Irbid, Jordan

Al-Abadsah, A. (2014) the direction and political practice and their relationship to aggression and the tendency towards social strength among the students of the Islamic University in Gaza, The Islamic University of Educational and Psychological Studies, Volume 22, No. 1, pp. 203-230.

Al-Bishri, M. (2010) Educational values included in the reading books that are scheduled in the secondary school, Studies in Curriculum and Teaching Methods, No. 156, pp.13-66 
Al-Dahiri, Saleh (2011) the basics of educational psychology and learning theories, Issue (1), Amman: Dar Al-Hamed.

Al-Jadoo, E. (2015) trends of special education students towards their specialization among a sample of students of Islamic sciences in Jordan, Educational Science Studies, Vol. 42, No. (3)

Alrfou, J. (2018) the degree of consideration of the Arabic language books for the basic stage of the higher psychological foundations from the point of view of teachers. unpublished master thesis, Al Hussein University, Maan, Jordan.

Alsamair, M. (1994) the extent to which the Arabic language books are considered for the first three grades of the psychological foundations from the point of view of the teachers, Unpublished Master Thesis, University of Yarmouk, Irbid: Jordan.

Amal, M. (2015) Principles of Growth Psychology, Egypt: International House for publishing and distribution

Ashour, Q. (2004) Distribution of the value system in the elements of the content of our beautiful language book for the students of the first four grades in Jordan. Journal of the Faculty of Education and Psychology, Issue (29), No. 4, Faculty of Education, Ain Shams University: Zahraa Al Sharq Library.

Assaed, M. (1998) Methods of Teaching Arabic Language, Damascus: Damascus University Publications

Batayneh, R. (2004) The extent to which the books of social and national education for the secondary stage in Jordan are taken into consideration for the criteria of the social bases of the curriculum and the development of an educational unit in light of these principles. Unpublished PhD thesis, Yarmouk University, Irbid, Jordan

Fayoumi, Kh. (2006) the level of representation of the Arabic language books in the primary stage in Jordan for the philosophical and psychological foundations of the curriculum. Unpublished PhD Dissertation, University of Jordan: Jordan.

Hammadneh, A., \&BaniKhaled, M. (2011) The extent to which Arabic language books are considered in the first four grades of basic education in Jordan from the point of view of teachers to the characteristics of developmental students. Studies in Educational Sciences, Vol. (38), Supplement (4).

Joan, et.al (2016) Top 20 Psychological principles for pk- 12 Education, theory into practice, Vol,55., pp.86-93.

Mekhemer, S. (2013) Psychological, social and educational needs of gifted students from their point of view and from the point of view of their teachers in Gaza City. Al-Aqsa University Journal, Human Sciences Series, Volume (7), No. (1), pp. $107-153$.

Ministry of Education (1988) First National Conference for Educational Development, Teacher's Message, vol. 1, No. 24, pp. 66-67

Ministry of Education (2007) Reference book in the preparation of curricula and the writing of textbooks, and learning resources, management of textbooks and school curricula, Amman, Jordan.

Ministry of Education (2015) Educational Development Conference, Amman, Jordan

Ministry of Education (2013) General framework and general and special productions of the Arabic language for the two stages of education: Basic and secondary, Curriculum and textbooks management, Amman, Jordan.

Saudi, Kh. \& Al Hawamdeh, A. (2016) the extent to which the books of Islamic education for the first three grades taking into consideration the psychological foundations from the teachers point of view in Jordan. Jordanian Educational Journal, Vol. (1), issue (1).

Shammari, Th. (2005) the extent to which the geography books for the higher elementary stage take into consideration the psychological foundations of the curriculum from the point of view of teachers and principals in the province of Hafr al-Batin in the Kingdom of Saudi Arabia, unpublished master thesis. University of Jordan: Jordan.

Talafha, H. (2013) Curriculum: planning, developing, implementing, Vol. 1, Amman: Dar Al Radwan for Publishing and Distribution. 